Research Article

\title{
Conformal Quad-Port UWB MIMO Antenna for Body-Worn Applications
}

\author{
Thennarasi Govindan, ${ }^{1}$ Sandeep Kumar Palaniswamy $\mathbb{D}^{1},{ }^{1}$ Malathi Kanagasabai ${ }^{1}{ }^{2}$ \\ Sachin Kumar $\mathbb{D}^{1},{ }^{1}$ Thipparaju Rama Rao $\mathbb{D}^{1},{ }^{1}$ and Mohammed Gulam Nabi Alsath $\mathbb{D}^{3}$ \\ ${ }^{1}$ Department of Electronics and Communication Engineering, SRM Institute of Science and Technology, \\ Kattankulathur 603203, India \\ ${ }^{2}$ Department of Electronics and Communication Engineering, College of Engineering, Guindy, Anna University, \\ Chennai 600025, India \\ ${ }^{3}$ Department of Electronics and Communication Engineering, SSN College of Engineering, Chennai 603110, India \\ Correspondence should be addressed to Sandeep Kumar Palaniswamy; vrpchs@gmail.com
}

Received 23 July 2021; Revised 23 November 2021; Accepted 1 December 2021; Published 30 December 2021

Academic Editor: Mourad Nedil

Copyright (C) 2021 Thennarasi Govindan et al. This is an open access article distributed under the Creative Commons Attribution License, which permits unrestricted use, distribution, and reproduction in any medium, provided the original work is properly cited.

\begin{abstract}
A conformal four-port multiple-input-multiple-output (MIMO) antenna operating at $2.4 \mathrm{GHz}$ and ultrawideband (UWB) is presented for wearable applications. The unit element of the MIMO antenna is a simple rectangular monopole with an impedance bandwidth of $8.9 \mathrm{GHz}(3.1-12 \mathrm{GHz})$. In the monopole radiator, stubs are introduced to achieve $2.4 \mathrm{GHz}$ resonance. Also, a defect is introduced in the ground plane to reduce backside radiation. The efficiency of the proposed antenna is greater than $95 \%$, and its peak gain is $3.1 \mathrm{dBi}$. The MIMO antenna has an isolation of $>20 \mathrm{~dB}$, and the estimated specific absorption rate (SAR) values for 1 gm of tissue are below $1.6 \mathrm{~W} / \mathrm{Kg}$. The size of the four-port MIMO antenna is $1.38 \lambda_{0} \times 0.08 \lambda_{0} \times 0.014 \lambda_{0}$.
\end{abstract}

\section{Introduction}

Wearable technology is one of the most popular research topics these days as it provides useful information about the fitness of a person. Wearable technology has been widely used in a variety of fields such as medicine, military, sports, and communication [1]. Body-worn devices such as fitness bands, smartwatches, smart jewellery, and smart helmets are commonly used for health monitoring. The antennas used in these smart devices operate at $2.45 \mathrm{GHz}$ ISM band and ultrawideband (UWB) [2]. In [3], a male finger ring antenna was designed for healthcare applications. In [4], an UWB antenna was reported for the indoor positioning systems. Antennas used in wearable devices should be lightweight, flexible, and conformal [5]. In [6], a button-shaped wearable antenna was designed that can be attached to clothing. In [7], the multilayer weaving method was used to create a textile antenna made of conductive threads. UWB antennas integrated with the $2.45 \mathrm{GHz}$ frequency band were reported in
$[8,9]$ to achieve a high data rate using small transmit power. A UWB multiple-input-multiple-output (MIMO) configuration was proposed to provide reliable data transmission while avoiding multipath fading. However, the mutual coupling is the main problem in MIMO antennas. The use of decoupling structures to reduce mutual coupling in a wideband vehicular antenna was described in [10]. Another important feature of wearable antennas is their close proximity to the human body. Therefore, specific absorption rate (SAR) analysis is performed to confirm that the radiation exposure is within the prescribed limit [11].

In this paper, a four-port $\mathrm{MIMO} /$ diversity wristband antenna is designed on a flexible and conformable silicone rubber substrate. The MIMO antenna consists of four antenna elements that are placed horizontally to provide pattern diversity. This paper is organized as follows. Section 2 describes the design of the proposed wearable antenna. Section 3 discusses the MIMO antenna results, diversity characteristics, and the SAR analysis. Section 4 presents the conclusion of the proposed work. 


\section{Antenna Design}

2.1. UWB Antenna Element. The proposed antenna is a rectangular monopole with a defect in the ground plane as shown in Figures 1(a) and 1(b), respectively. The evolution of the proposed antenna is depicted in Figure 2. Figure 2(a) consists of a simple rectangular radiator and a modified ground plane. However, Antenna 1 has poor impedance matching, as illustrated in Figure 3. In the next step, rectangular slots are etched from the radiator on both sides of the feed line to improve impedance matching, as shown in Figure 2(b) (Antenna 2). In Figure 2(c) (Antenna 3), a $\mathrm{U}$-shaped slot is incorporated into the ground plane to further improve the impedance matching. This step increased the impedance bandwidth significantly. Furthermore, a meander line stub and rectangular slot are introduced in the radiator and ground plane, respectively, to achieve an extra resonance at $2.4 \mathrm{GHz}$, as illustrated in Figure 2(d)(Antenna 4). Table 1 displays the design parameters of the proposed antenna.

For a better understanding, the surface current distribution of the proposed antenna element at $2.4 \mathrm{GHz}, 3 \mathrm{GHz}, 6 \mathrm{GHz}$, and $10 \mathrm{GHz}$ is shown in Figure 4. It is observed that the UWB is controlled by the rectangular monopole radiator, while the $2.4 \mathrm{GHz}$ resonance is controlled by the meander line stub and slotted ground plane. The antenna is designed on the silicone rubber substrate material of dielectric constant of 2.9 and loss tangent of 0.358 [12]. The substrate material has a perimeter of $1.38 \lambda_{0}$, with a bending radius of $16.0825 \mathrm{~mm}$ readily available adult size silicone rubber wristband in the market. The proposed antenna operates in the $(2.05-2.6 \mathrm{GHz})$ ISM band and the $(3.1-12 \mathrm{GHz}) \mathrm{UWB}$ band. The size of the antenna element is $0.437 \lambda_{g} \times 0.025 \lambda_{g} \mathrm{~mm}^{2}$, where $\lambda_{g}$ is the guided wavelength.

The lower band-edge frequency $\left(f_{l}\right)$ of the monopole planar antenna is determined using the following equation $[13,14]$ :

$$
f_{l}=\frac{7.2}{(l+r+p) \times k},
$$

where $l$ is the height of the antenna, $r$ denotes the width of the monopole antenna, and $p=0.2 \mathrm{~cm}$ is the distance between the radiator and the ground plane.

$$
k=\sqrt[4]{\varepsilon_{e f f}} .
$$

The fourth root of the effective dielectric constant is the factor $k$.

Equation (1) is restructured for the proposed wristband antenna as follows:

$$
f_{l}=\frac{7.2}{(1.92 \pi[(a+b)]+p) \times k} .
$$

The expression $(1+r)$ is related to $1.92 \pi[(a+b)]$, which is equivalent to the perimeter of the monopole radiator. $a$ and $b$ correspond to the semiwidth and semilength of the radiator. The parameters $a, b, l, r$, and $p$ are measured in centimetres, and $f_{l}$ is measured in $\mathrm{GHz}$.

The $2.45 \mathrm{GHz}$ resonant frequency is obtained using a stub of length $\lambda_{o} / 4=L 1+L 2+L 3+\ldots . .+L 17$ as depicted in Figure 5.
The above equations are accompanied with the equivalent circuit as given in Figure 6.

Figure 6 shows the equivalent circuit of the proposed antenna, which is made up of R, L, and C components. The antenna impedance characteristics (Figure 7) show the series and parallel layout of the equivalent circuit. It is considered a series connection when the real and imaginary curves are from low to high, and a parallel connection if they move from high to low [15]. The values of the $\mathrm{R}, \mathrm{L}$, and $\mathrm{C}$ components are depicted in Figure 6. Since the impedance curves move from high to low at $2.4 \mathrm{GHz}$, they are shown in parallel, and the impedance curves go from low to high at $3.1 \mathrm{GHz}$ (the start of the UWB) and $10.6 \mathrm{GHz}$ (the end of the UWB), they are represented in series.

A parametric analysis of the radiator and ground plane is performed to achieve $2.4 \mathrm{GHz}$ and UWB, as shown in Figures 8-11. The length of the stub " $o$ " is varied to achieve the $2.4 \mathrm{GHz}$ ISM band. When " $o$ " is decreased to $0.4 \mathrm{~mm}$, the reflection coefficient curve shifts to the left, and when " $O$ " is greater than $0.5 \mathrm{~mm}$, the reflection coefficient curve shifts to the right. Figure 6 depicts the effect of parameter " $f$." The reflection coefficient curves show that when " $f$ " increases, the impedance matching improves, resulting in the UWB. Figure 10 depicts the effect of ground plane parameter " $q$." It is evident that as " $q$ " increases, the resonance bandwidth increases due to improved impedance matching. Figure 11 depicts the reflection coefficients for various slot lengths " $r$." When $r=1.5 \mathrm{~mm}$, the UWB is obtained, but no resonance occurs in the $2.4 \mathrm{GHz}$ ISM band. Whereas at $r=2.5 \mathrm{~mm}$, the $2.4 \mathrm{GHz}$ ISM band is obtained, but the reflection coefficient curve shifts towards the higher frequency side. Therefore, the optimal width of the slot should be $2 \mathrm{~mm}$.

2.2. MIMO Antenna. The proposed wristband MIMO antenna with and without ground plane is depicted in Figure 12. As [16], the investigations on connected ground plane are conducted, and the S-parameter results (Figure 13) show that there is no discernible effect on the performance of the proposed MIMO antenna due to the conformal nature of the prototype. The spacing between the antenna elements is $0.07 \lambda_{0}$, which offers interelement isolation of $>20 \mathrm{~dB}$. A parametric analysis of the wristband antenna is performed by varying the bending radius. The bending radius of $16.0825 \mathrm{~mm}$ is chosen as adult size silicone rubber wristbands of this size are readily available in the market.

The parametric analysis is conducted by varying the bending radius, and the S-parameter curves are shown in Figures 14 and 15. Figure 14 demonstrates that the reflection coefficients for seven different bending radii do not vary significantly, and all of these curves covered the UWB and $2.4 \mathrm{GHz}$ band. However, the spacing between the antenna elements may vary due to changes in the bending radius. The spacing is reduced to $0.0385 \lambda_{0}$ for a bending radius of $14.5825 \mathrm{~mm}$ in Case 1 and increased to $0.105 \lambda_{0}$ for a bending radius of $17.5825 \mathrm{~mm}$ in Case 2. It is observed that the interelement isolation increases with a larger bending radius and decreases with a smaller bending radius, shown in Figure 15. Further reduction of bending radius below 

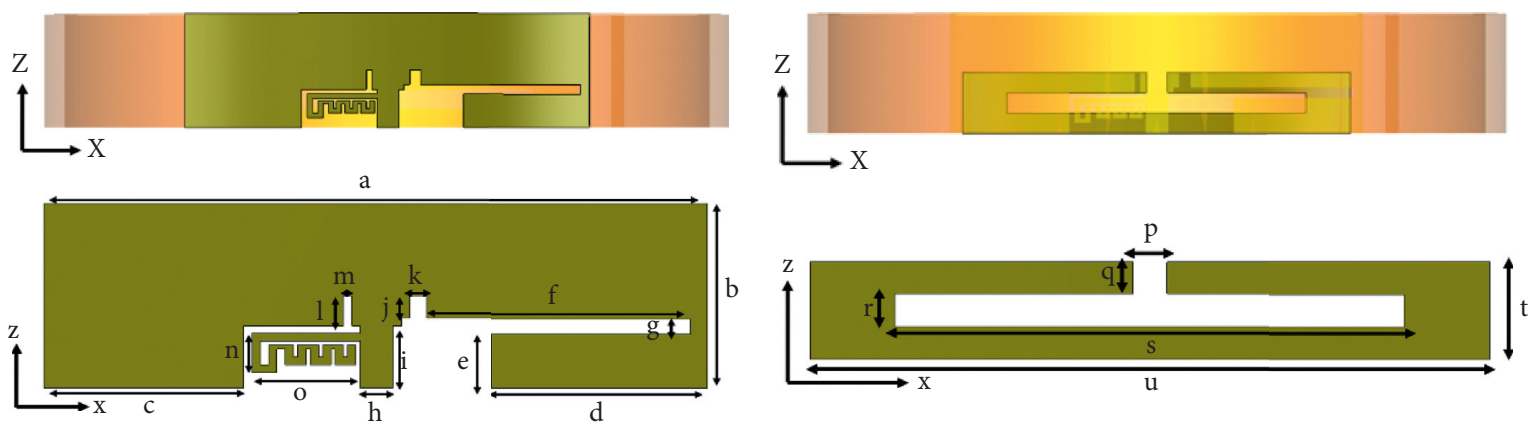

(a)

(b)

FIGURE 1: Proposed wristband antenna: (a) front view and (b) rear view.

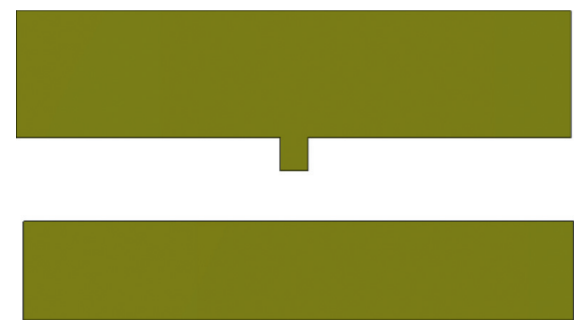

(a)
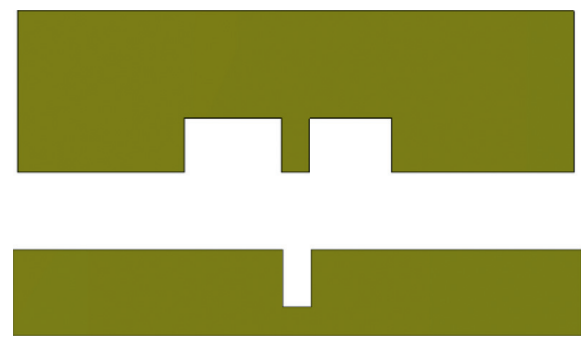

(c)
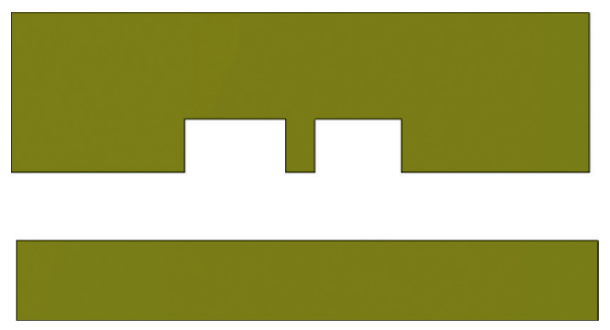

(b)

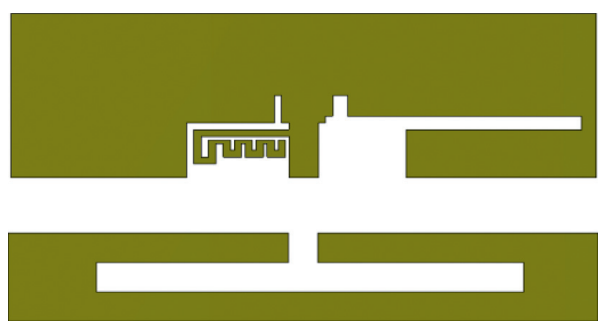

(d)

Figure 2: Evolution of the proposed antenna: (a) Antenna 1, (b) Antenna 2, (c) Antenna 3, and (d) Antenna 4.

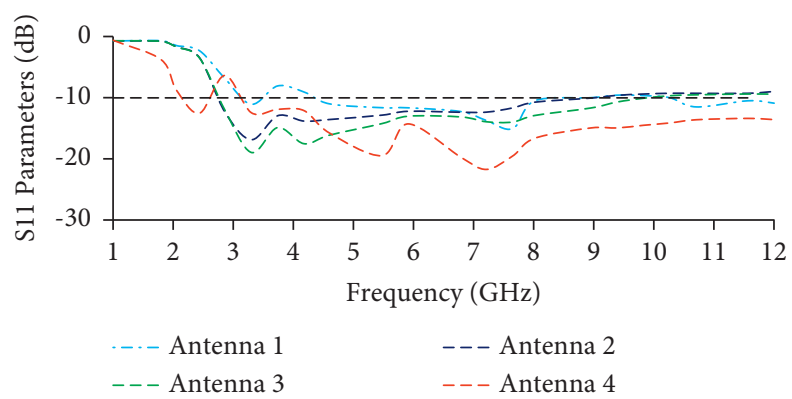

Figure 3: Reflection coefficients of the evolution stages.

TABle 1: Dimensions of the wristband antenna.

\begin{tabular}{lccccccccccc}
\hline Parameter & $a$ & $b$ & $c$ & $d$ & $e$ & $f$ & $g$ & $h$ & $i$ & $j$ \\
\hline Value $(\mathrm{mm})$ & 40 & 12 & 12 & 13 & 3.5 & 16 & 1 & 2 & 4 & 1.5 & 1 \\
Parameter & $l$ & $m$ & $n$ & $o$ & $p$ & $q$ & $r$ & $s$ & $t$ & $u$ & \\
Value $(\mathrm{mm})$ & 2 & 0.5 & 6.25 & 0.5 & 2 & 2 & 2 & 30 & 6 & 40 & \\
\hline
\end{tabular}



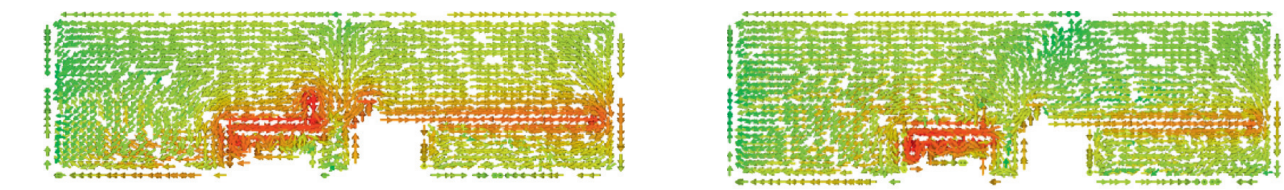

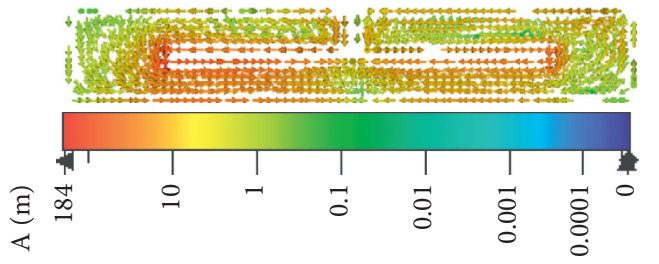

(a)

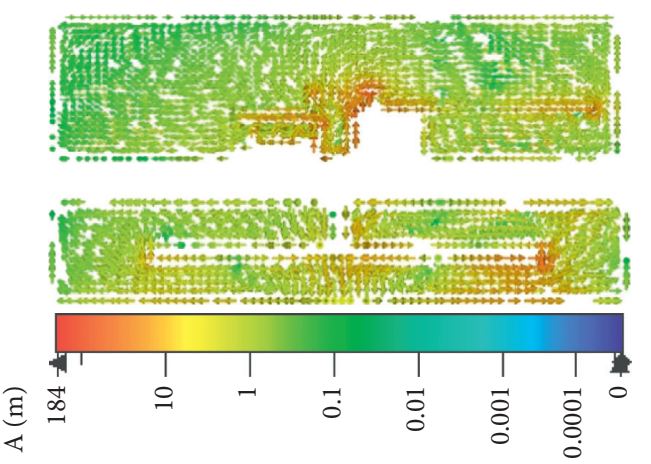

(c)

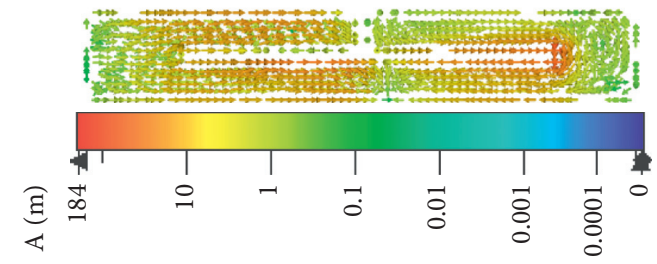

(b)
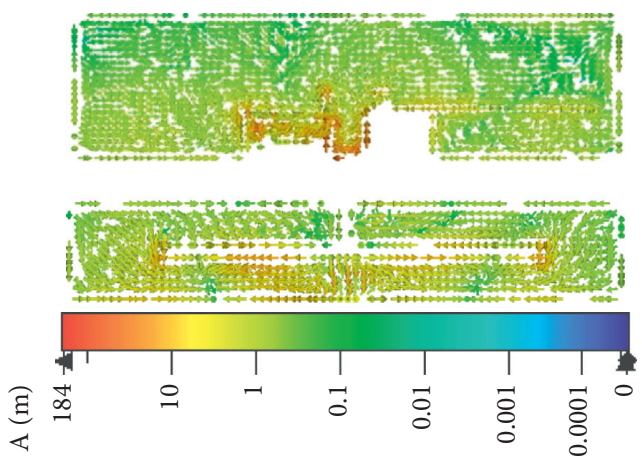

(d)

FIgURE 4: Surface current distribution at (a) $2.4 \mathrm{GHz}$, (b) $3 \mathrm{GHz}$, (c) $6 \mathrm{GHz}$, and (d) $10 \mathrm{GHz}$.

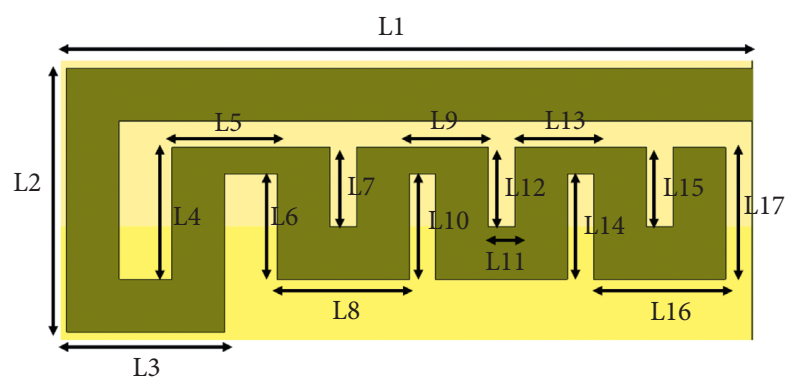

Figure 5: Stub of length $\lambda_{o} / 4$ to achieve $2.45 \mathrm{GHz}$ resonant frequency.

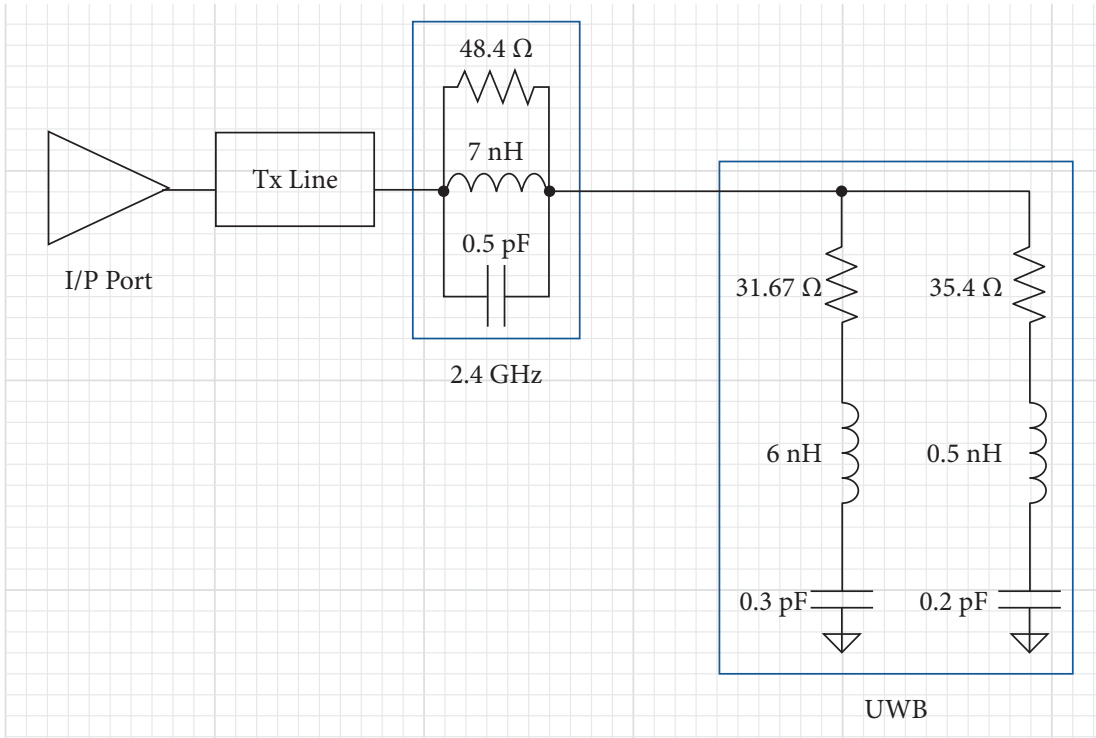

FIgURE 6: Equivalent circuit of the proposed wristband antenna. 


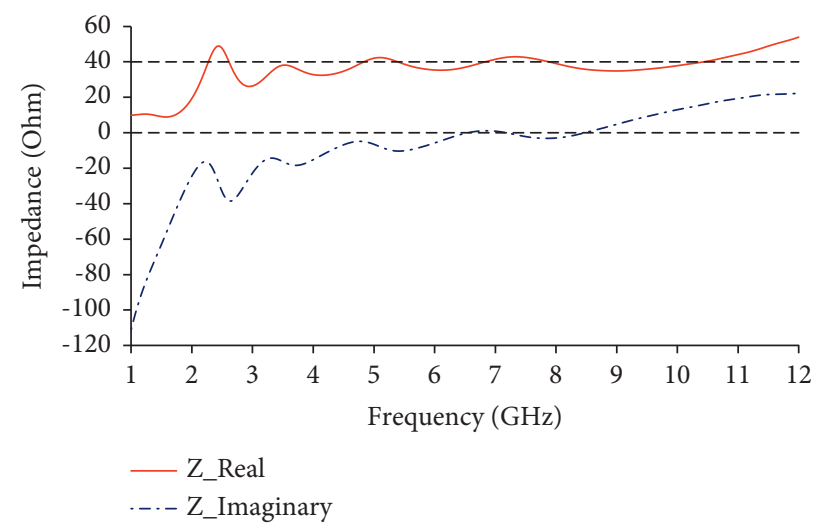

FIGURE 7: Impedance characteristics of the proposed wristband antenna.

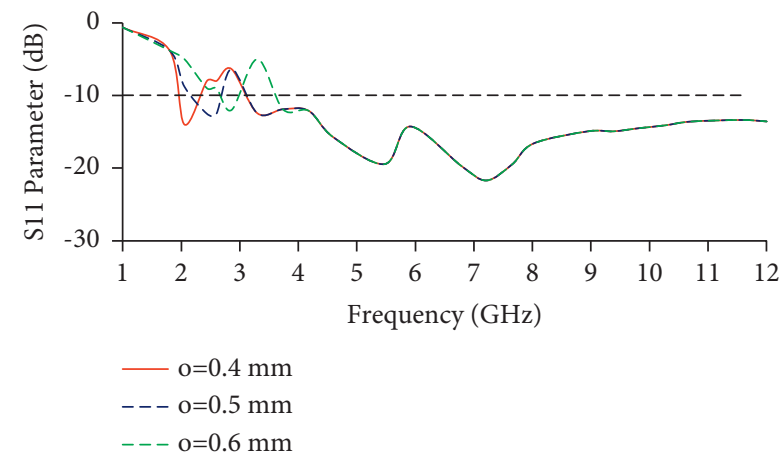

FIGURE 8: Reflection coefficients with varying lengths of stub “o."

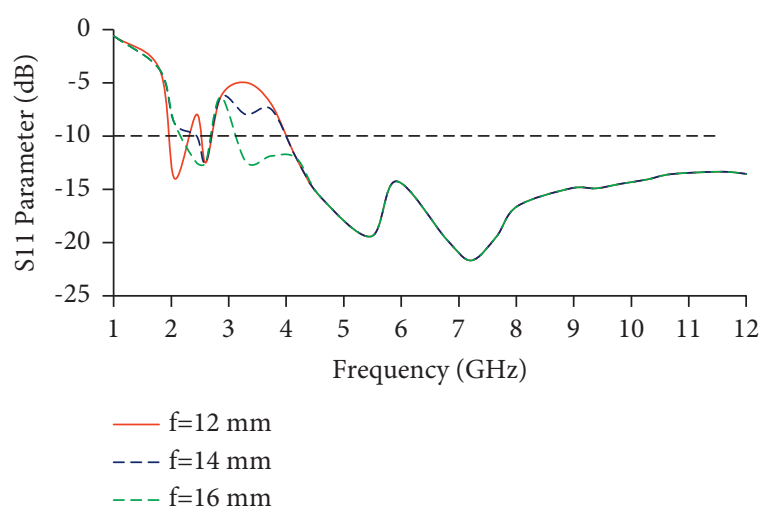

Figure 9: Reflection coefficients with varying lengths of " $f$."

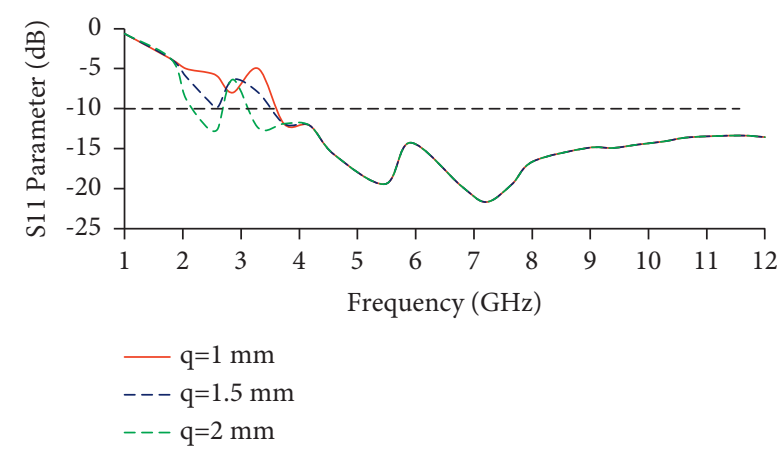

Figure 10: Reflection coefficients with varying lengths of slot " $q$. .

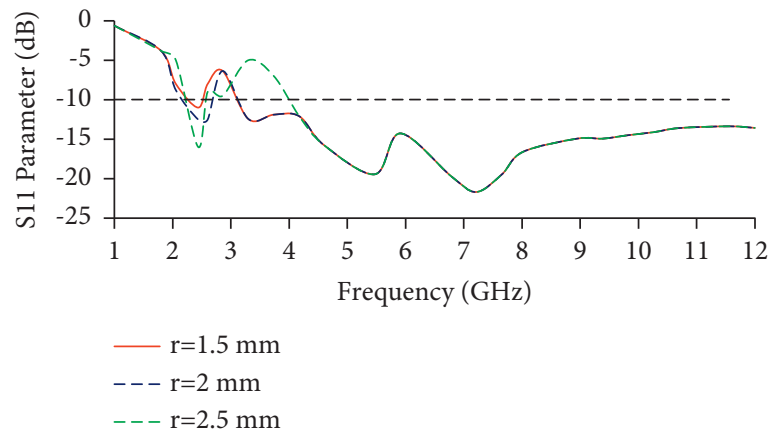

FIGURE 11: Reflection coefficients with varying lengths of slot " $r$."

$14.5825 \mathrm{~mm}$ increases the mutual coupling, which affects the antenna's performance. There is no use of increasing the band size further as it will not match with the market available wristband. Therefore, band size with a bending radius of $16.0825 \mathrm{~mm}$ is considered in the proposed work.

\section{Results and Discussion}

3.1. S-Parameters. Figures 16(a)-16(c) show the fabricated prototype and its $S$-parameter measurement on the Anritsu MS 2037C vector network analyzer. The simulated and measured $S$-parameters of the MIMO antenna are given in Figures 17 and 18. The antenna exhibits an impedance bandwidth of $2.05-2.6 \mathrm{GHz}$ in the ISM band and $3.1-12 \mathrm{GHz}$ in the UWB. The refection coefficient curves for Antenna 1, Antenna 2, Antenna 3, and Antenna 4 are all similar; therefore, $S_{11}$ is only shown at port-1 for brevity. Figure 18 shows the mutual coupling between the antenna elements, which is greater than $20 \mathrm{~dB}$.

3.2. Radiation Performance. The proposed antenna is tested in an anechoic chamber with a horn antenna as the standard reference antenna. The anechoic chamber measurement setup is shown in Figure 19. Figure 20 depicts the radiation patterns obtained in free space and on the human wrist at $2.4 \mathrm{GHz}, 3 \mathrm{GHz}, 6 \mathrm{GHz}$, and $10 \mathrm{GHz}$. The radiation patterns on the human wrist show suppressed back radiations.

The gain and efficiency plots of the proposed antenna are shown in Figure 21. The simulated and measured peak gain 


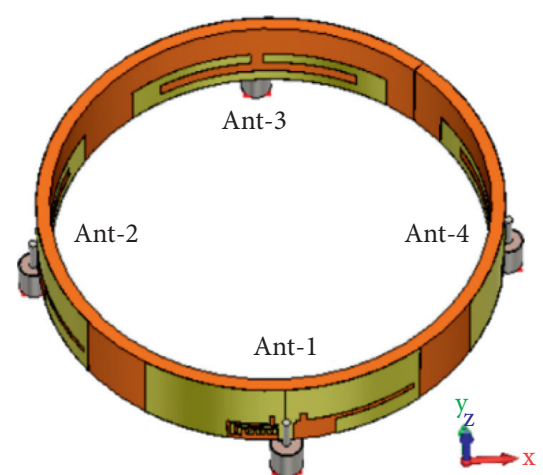

(a)

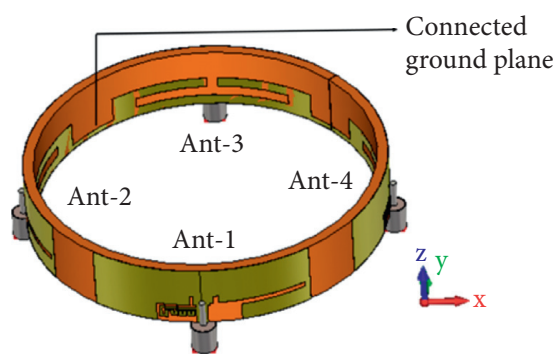

(b)

Figure 12: Prototype of the wristband antenna (a) without common ground plane and (b) with common ground plane.

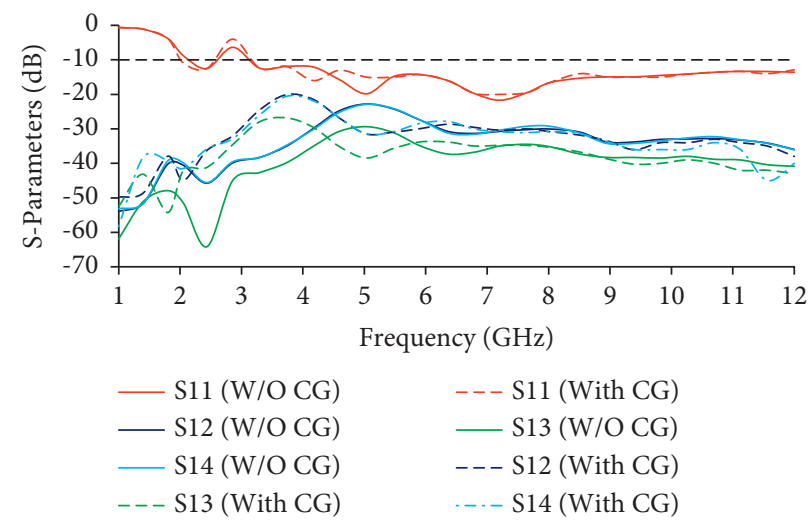

FIGURE 13: Simulated S-parameters of the proposed wristband antenna (with and without CG (common ground) plane).

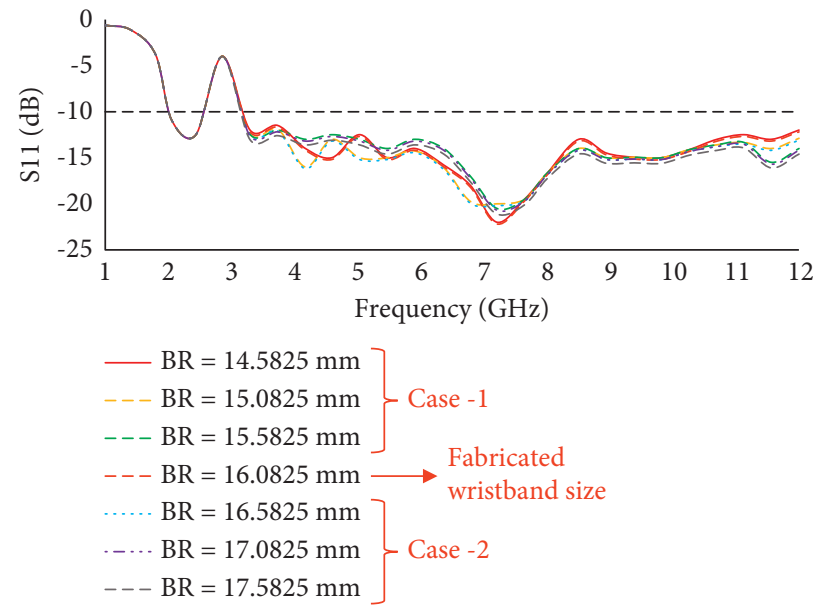

FIGURE 14: Reflection coefficients of the proposed wristband antenna at different bending radii (BR).

values are $4.7 \mathrm{dBi}$ and $3.1 \mathrm{dBi}$, respectively. The difference between simulated and measured gain values is due to the manual fabrication process, cable effect, and SMA connector soldering $[17,18]$. It may also be due to conductive adhesives used during fabrication and the tapes during anechoic chamber measurements. Other losses, such as conductor, dielectric, surface radiation, and power leakage from the connector, are also present in the measurements, which were almost negligible in the simulated results. The efficiency of the wristband antenna is greater than $95 \%$.

3.3. Diversity Performance. Envelope correlation coefficient (ECC) is used to calculate the correlation between antenna elements. It can be calculated using far-field as follows [19]: 


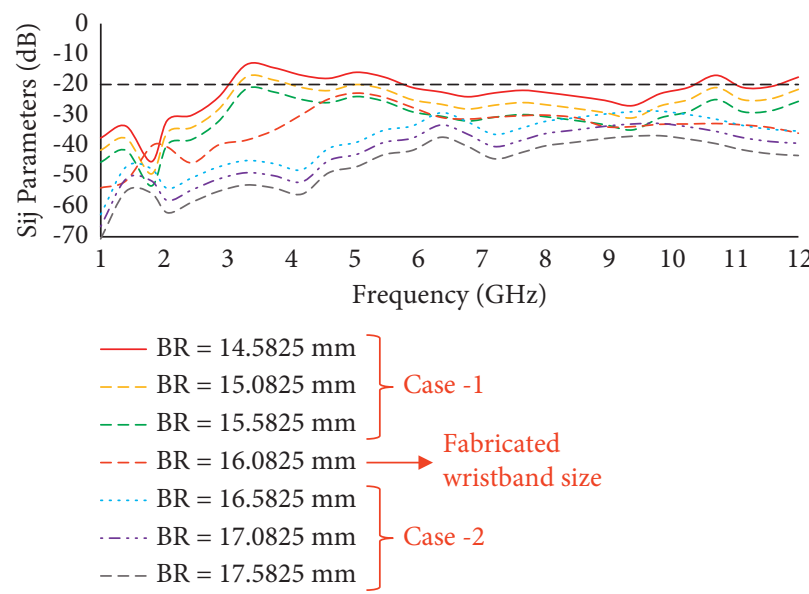

FIGURE 15: Mutual coupling of the proposed wristband antenna at different bending radii (BR).

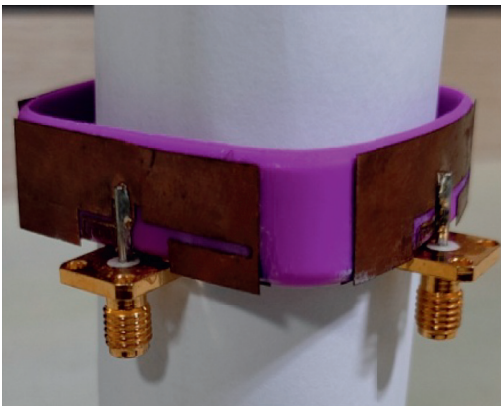

(a)

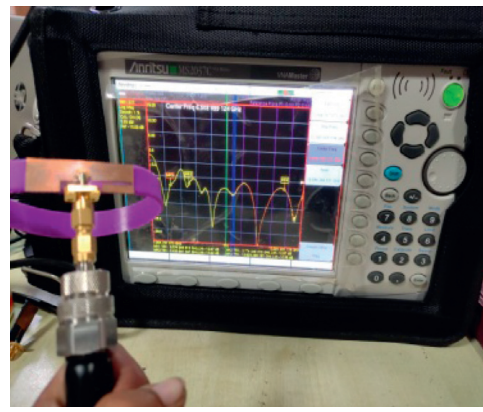

(b)

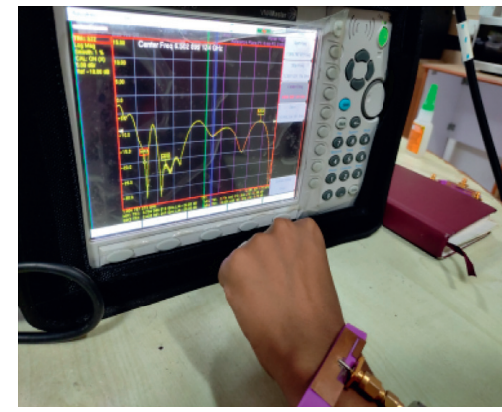

(c)

Figure 16: (a) Photograph of the fabricated prototype, (b) antenna measurement in free space, and (c) antenna measurement on the human wrist.

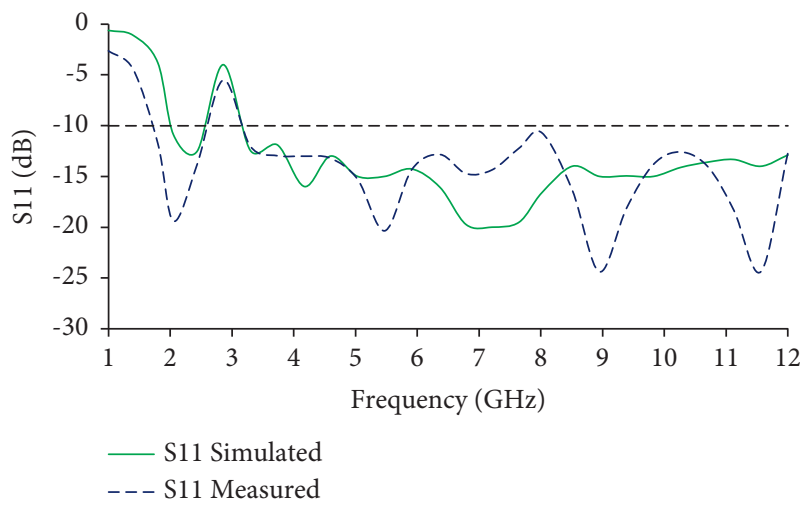

FIGURE 17: Simulated and measured $S_{11}$ of the proposed wristband antenna.

$$
E C C=\frac{\left|\iint\left[\overrightarrow{F_{1}}(\theta, \varphi) \cdot \overrightarrow{F_{2}}(\theta, \varphi)\right] d \Omega\right|^{2}}{\iint\left|\overrightarrow{F_{1}}(\theta, \varphi)\right|^{2} d \Omega \iint\left|\overrightarrow{F_{2}}(\theta, \varphi)\right|^{2} d \Omega} .
$$

The ECC of the antenna is shown in Figure 22, and the obtained ECC values are $<0.1$. Diversity gain (DG) refers to the process of transmitting a signal with the minimum loss. It is obtained by using (5). The DG plots are shown in

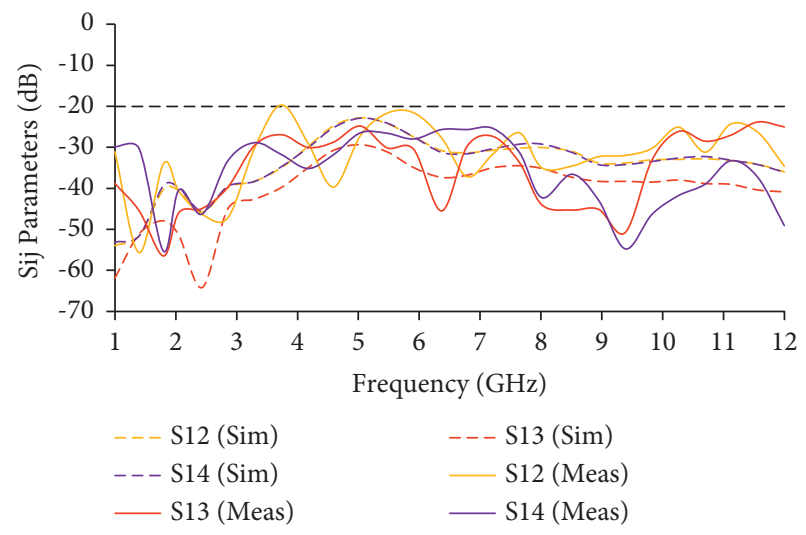

FIGURE 18: Simulated and measured $S_{i j}$-parameters of the proposed wristband antenna.

Figure 23, and the DG of the proposed antenna is greater than $9.4 \mathrm{~dB}$.

$$
D G=\sqrt{1-|E C C|^{2}}
$$

Channel capacity loss (CCL) is a measure of channel loss in a MIMO system. CCL is calculated using the following equation [20]: 

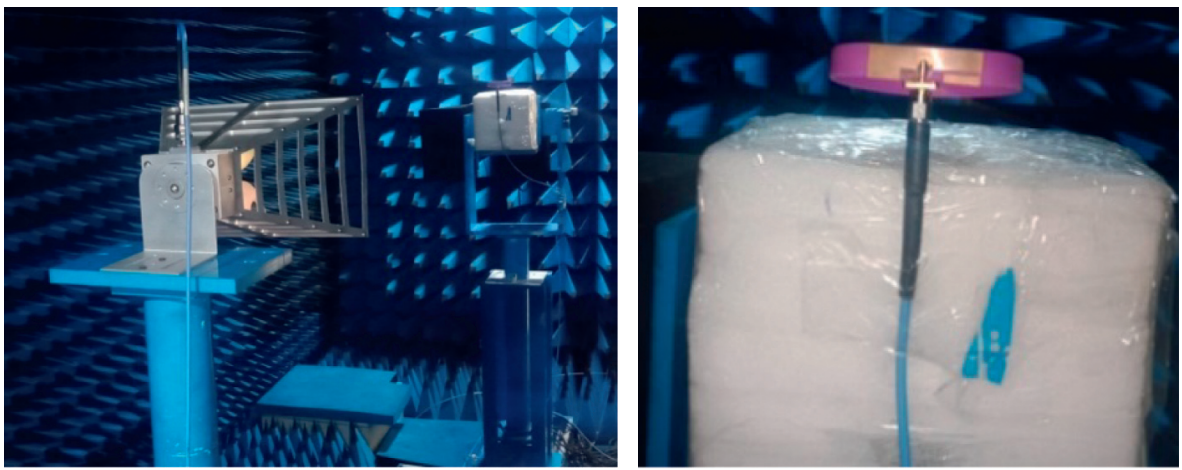

Figure 19: Anechoic chamber measurement of the proposed wristband antenna.

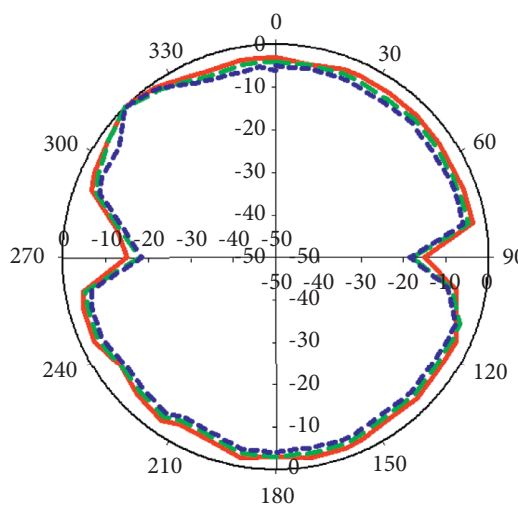

- On free space (sim)

- -- On free space (meas)

--- On human body (sim)

(a)

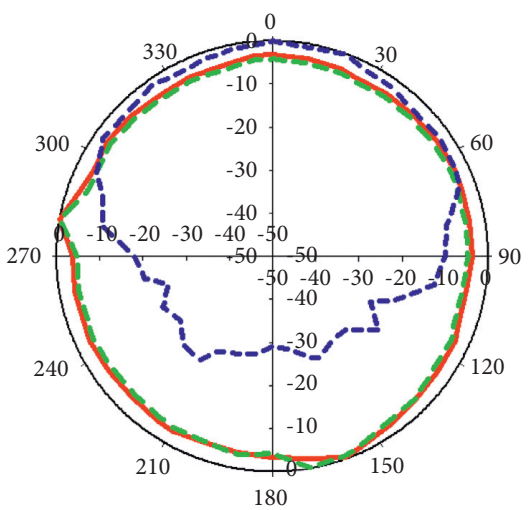

- On free space (sim)

- - - On free space (meas)

--- On human wrist (sim)

(d)

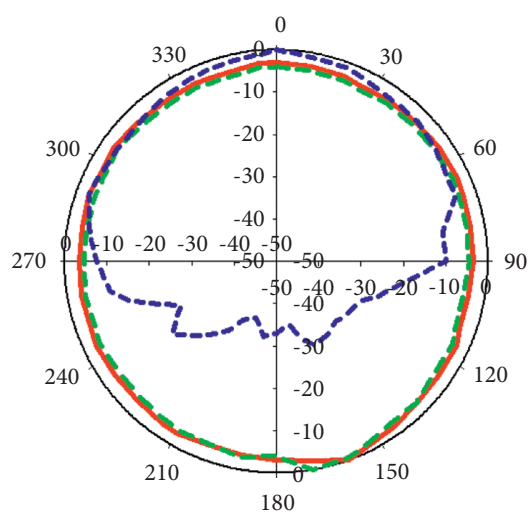

- On free space (sim)
- -- On free space (meas)
--- On human wrist (sim)

(b)

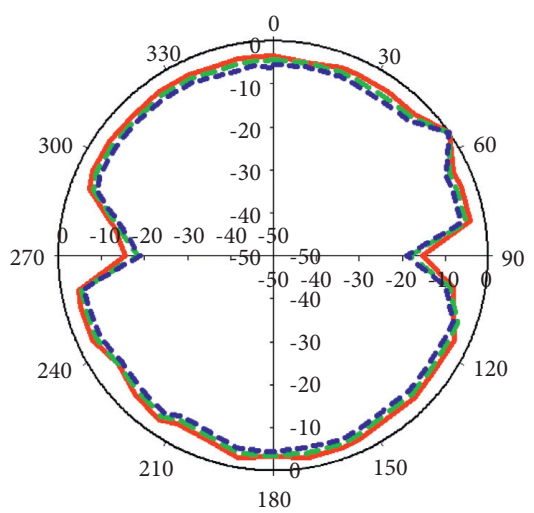

_- On free space (sim)

- - - On free space (meas)

--- On human wrist (sim)

(e)

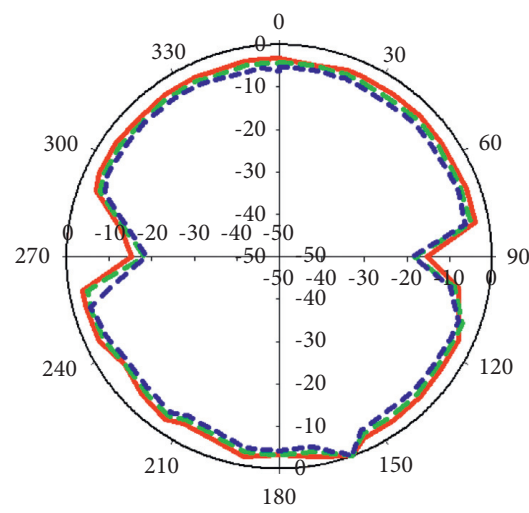

- On free space (sim)

--- On free space (meas)

--- On human wrist (sim)

(c)

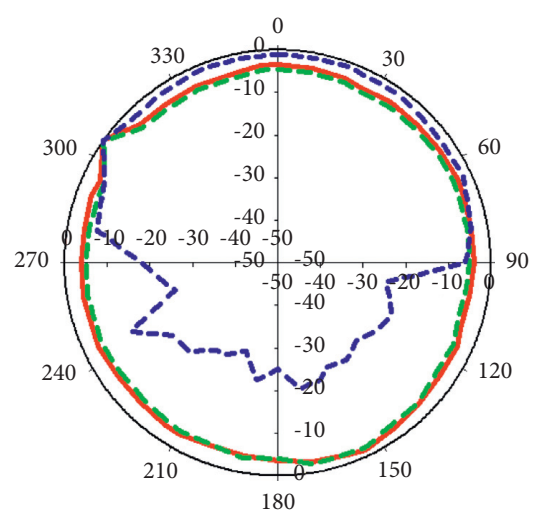

— On free space (sim)

- - - On free space (meas)

--- On human wrist (sim)

(f)

Figure 20: Continued. 


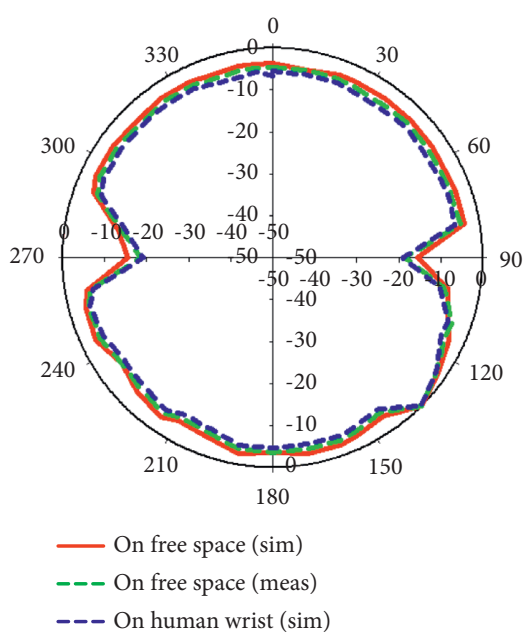

(g)

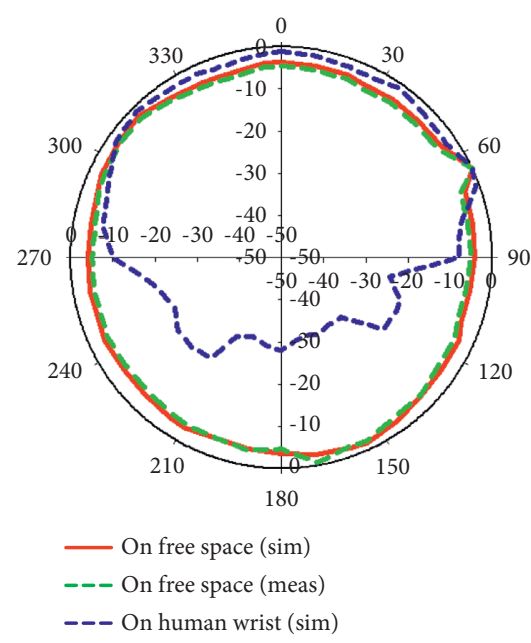

(h)

FIGURE 20: Radiation patterns of the proposed wristband antenna: (a) $2.4 \mathrm{GHz}$, E-plane, (b) $2.4 \mathrm{GHz}$, H-plane, (c) $3 \mathrm{GHz}$, E-plane, (d) $3 \mathrm{GHz}$, H-plane, (e) $6 \mathrm{GHz}$, E-plane, (f) $6 \mathrm{GHz}$, H-plane, (g) $10 \mathrm{GHz}$, E-plane, and (h) $10 \mathrm{GHz}, \mathrm{H}$-plane.

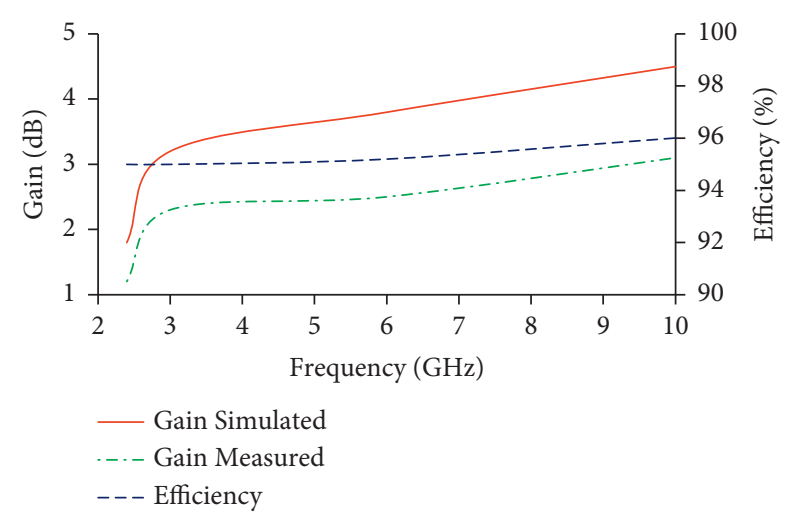

FIGURE 21: Gain and efficiency of the proposed wristband antenna.

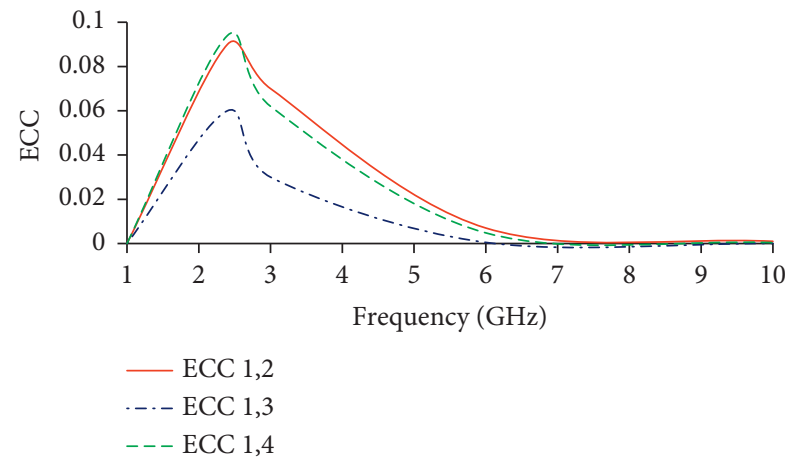

Figure 22: ECC of the proposed wristband antenna.

$$
C C L=-\log _{2}|\psi|^{R} .
$$

The total active reflection coefficient (TARC) is defined as the ratio of total reflected power $b_{i}$ to total incident power $a_{i}$, as given in the following equation [20]:

$$
T A R C=\frac{\sqrt{\sum_{i=1}^{N}\left|b_{i}\right|^{2}}}{\sqrt{\sum_{i=1}^{N}\left|a_{i}\right|^{2}}} .
$$

The measured CCL and TARC values are depicted in Figures 24 and 25.

3.4. SAR Analysis. In body-worn wearable applications, the radiated energy is absorbed by the human body. This can be evaluated by using SAR analysis. The simulations of the antenna on the cylindrical human body model (shown in Figure 26) are carried out using the CST Microwave Studio ${ }^{\circledR}$ software using an input power of 1 Watt. The characteristics of the human body tissue model are tabulated in Table 2.

The obtained SAR values at $2.4 \mathrm{GHz}, 3 \mathrm{GHz}, 6 \mathrm{GHz}$, and $10 \mathrm{GHz}$ frequencies are $0.191 \mathrm{~W} / \mathrm{Kg}, 0.195 \mathrm{~W} / \mathrm{Kg}, 0.718 \mathrm{~W} /$ $\mathrm{Kg}$, and $0.928 \mathrm{~W} / \mathrm{Kg}$, respectively, which are less than the Federal Communications Commission (FCC) limit of 1.6 W/Kg, shownin Figure 27. The wristband antenna is also simulated using a human wrist phantom as depicted in Figure 28. The SAR values at $2.4 \mathrm{GHz}, 3 \mathrm{GHz}, 6 \mathrm{GHz}$, and $10 \mathrm{GHz}$ are $0.308 \mathrm{~W} / \mathrm{Kg}, 0.329 \mathrm{~W} / \mathrm{Kg}, 0.543 \mathrm{~W} / \mathrm{Kg}$, and $0.873 \mathrm{~W} / \mathrm{Kg}$, respectively. The fabricated antenna prototype (shown in Figure 16(a)) is measured in free space and on a human wrist using the vector network analyzer, as shown in Figures 16(b) and 16(c), respectively. The simulated and measured reflection coefficients in free space and on the human body are depicted in Figure 29. It can be observed that both the simulated and measured reflection coefficients, in free space and on the human body, cover the $2.4 \mathrm{GHz}$ band and UWB.

Table 3 compares the proposed wristband antenna with the existing antenna designs. Table 3 shows that the proposed wristband antenna covers the UWB and $2.45 \mathrm{GHz}$ ISM band. The proposed antenna is conformal in comparison to the antenna designs reported in [21-25, 28, 29]. It 


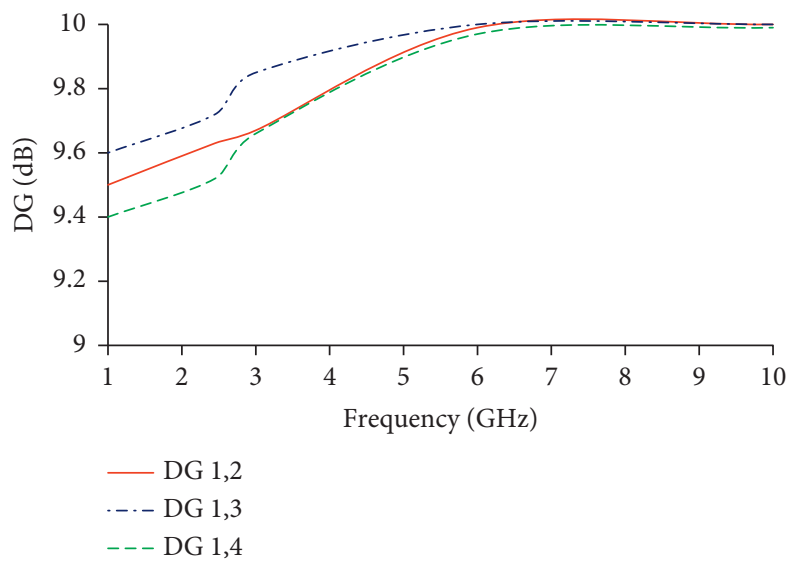

FIgURE 23: Diversity gain of the proposed wristband antenna.

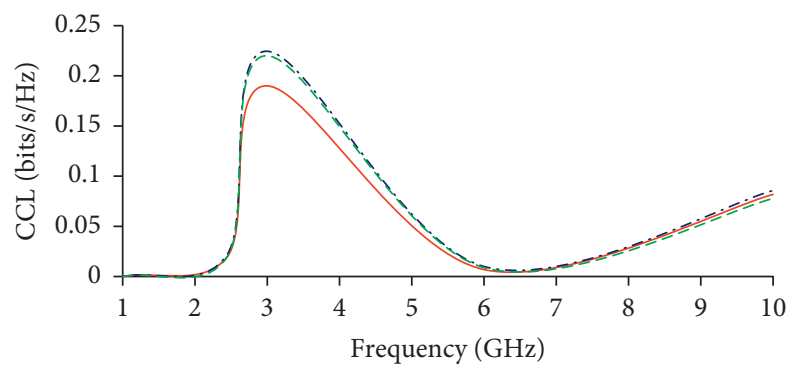

$-\operatorname{CCL} 1,2$

-... CCL 1,3

--- CCL 1,4

Figure 24: CCL of the proposed wristband antenna.

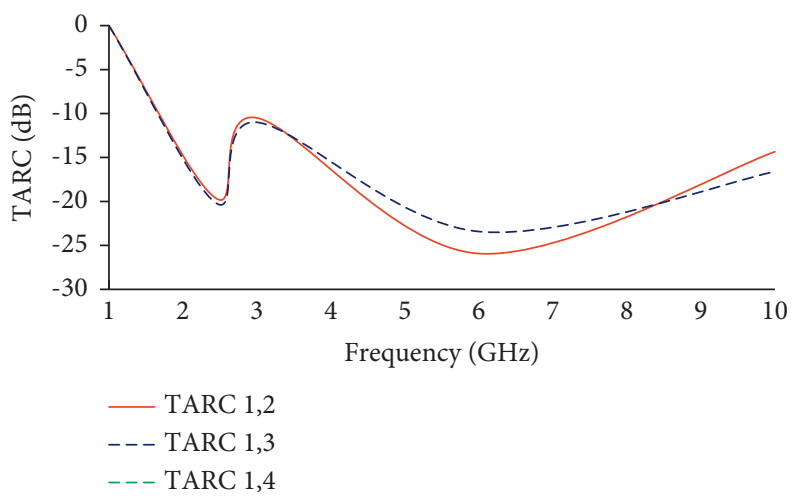

FIgURE 25: TARC of the proposed wristband antenna.

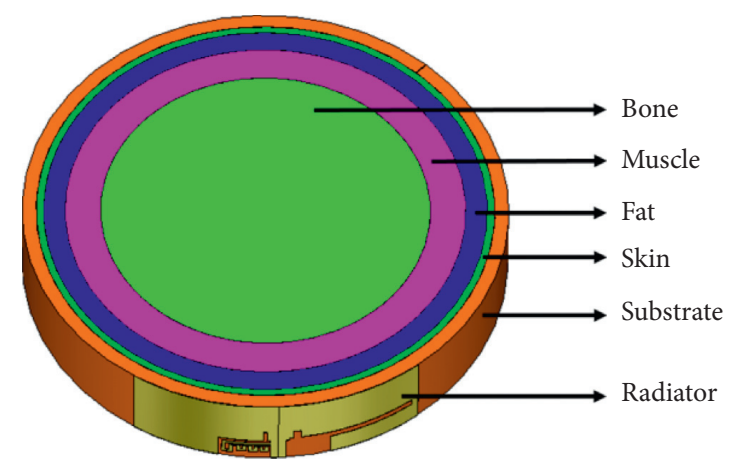

FIgURE 26: Cylindrical human body tissue model of the proposed wristband antenna. 
TABle 2: Characteristics of human body tissue.

\begin{tabular}{|c|c|c|c|c|}
\hline Cylindrical human layers & Frequency $(\mathrm{GHz})$ & Dielectric constant $\left(\varepsilon_{r}\right)$ & Loss tangent $(\tan \delta)$ & Thickness (mm) \\
\hline \multirow{4}{*}{ Skin } & 2.4 & 42.923 & 0.272 & 1 \\
\hline & 3 & 37.358 & 0.2786 & \\
\hline & 6 & 34.215 & 0.3584 & \\
\hline & 10 & 30.705 & 0.4806 & \\
\hline \multirow{4}{*}{ Fat } & 2.4 & 5.285 & 0.145 & 5 \\
\hline & 3 & 5.2138 & 0.15011 & \\
\hline & 6 & 4.8608 & 0.19612 & \\
\hline & 10 & 4.5572 & 0.23373 & \\
\hline \multirow{4}{*}{ Muscle } & 2.4 & 52.791 & 0.241 & 13 \\
\hline & 3 & 51.936 & 0.24804 & \\
\hline & 6 & 47.069 & 0.34935 & \\
\hline & 10 & 41.954 & 0.46476 & \\
\hline \multirow{4}{*}{ Bone } & 2.4 & 12.661 & 0.2524 & 12 \\
\hline & 3 & 8.35 & 0.1434 & \\
\hline & 6 & 7.73 & 0.173 & \\
\hline & 10 & 7.6 & 0.196 & \\
\hline
\end{tabular}
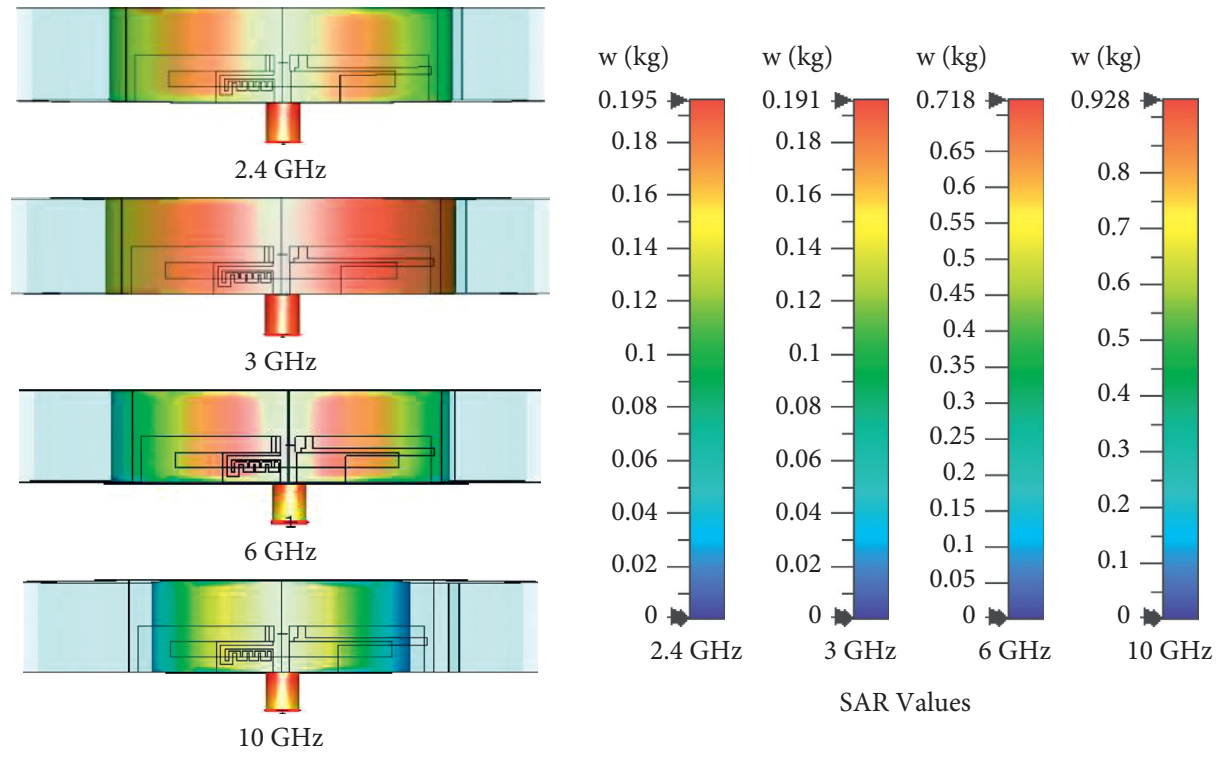

FIGURE 27: SAR values of the proposed wristband antenna using the cylindrical human tissue model.

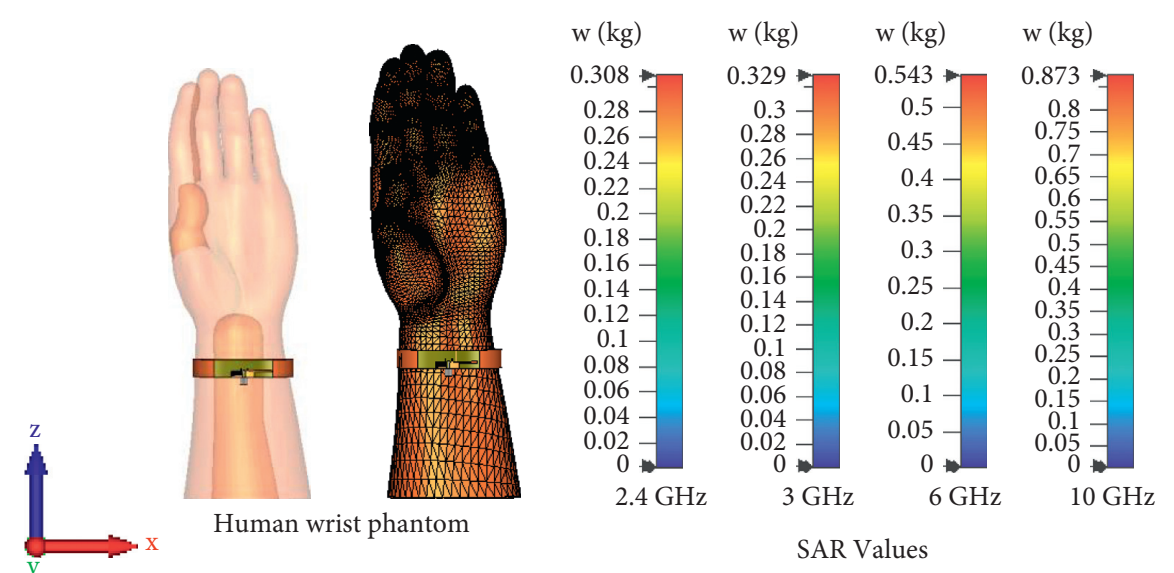

FIGURE 28: SAR values of the proposed wristband antenna on the human wrist phantom. 


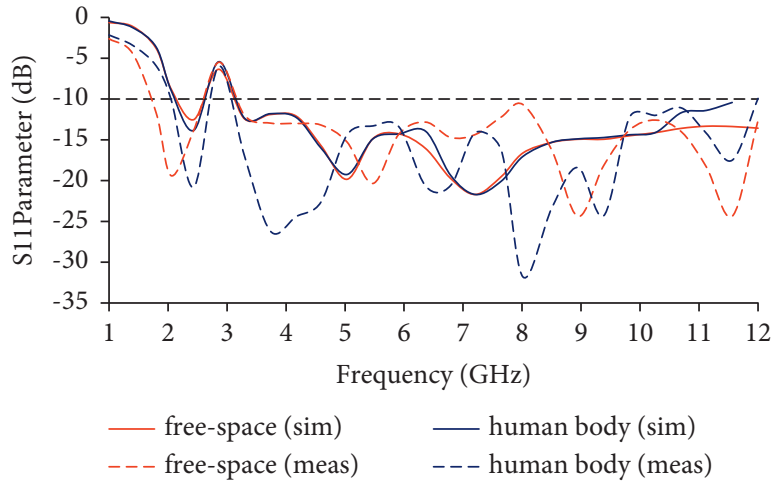

FIGURE 29: Reflection coefficients of the proposed wristband antenna in free space and on the human body.

TABLE 3: Comparison of the proposed wristband antenna with the existing designs.

\begin{tabular}{|c|c|c|c|c|c|c|}
\hline Ref. & Size $\left(\lambda_{g} \times \lambda_{g}\right)$ & Ports & Substrate & Bandwidth $(\mathrm{GHz})$ & Diversity type & Isolation $(\mathrm{dB})$ \\
\hline$\overline{[21]}$ & $0.616 \times 0.51$ & 4 & Plexi glass & $24.1-27.18,33-44.13$ & - & $>16$ \\
\hline [22] & $0.05 \times 0.05$ & 2 & Roger RO4003 C & $5.2-6.3$ & Polarization/pattern & $>22$ \\
\hline [23] & $0.443 \times 0.22$ & 8 & FR- 4 & $3.1-6$ & Spatial & $<10$ \\
\hline$[24]$ & $0.095 \times 0.014$ & 2 & FR-4 & $3.33-3.67$ & Pattern & $>14$ \\
\hline$[25]$ & $0.0148 \times 0.0148$ & 2 & RO4350 & $0.665-1.3,1.415-2,2.42-3.09,3.18-3.89$ & - & $>11.7$ \\
\hline [26] & $0.32 \times 0.32$ & 3 & Taconic TLY-5 & $4.63-5.87$ & Pattern & $>16.5$ \\
\hline [27] & $0.996 \times 0.126$ & 2 & Coloured plastic & $7.96-8.76$ & - & $>21$ \\
\hline [28] & $0.095 \times 0.095$ & 2 & FR-4 & $2.18-2.85$ & Polarization & $>13$ \\
\hline [29] & $0.214 \times 0.214$ & 4 & FR-4 & $1.71-3.94$ & - & $>26$ \\
\hline [30] & $0.158 \times 0.1$ & 2 & Jean & $2.74-12.33$ & - & $>26$ \\
\hline Prop. & $0.437 \times 0.025$ & 4 & Silicone rubber & $2.1-2.6,3.1-12$ & Pattern & $>22$ \\
\hline
\end{tabular}

also provides greater than $20 \mathrm{~dB}$ isolation when compared with the antenna configurations of $[21,23-26,28]$.

\section{Conclusion}

A body-worn wristband antenna is proposed in this work. The proposed MIMO antenna is composed of four horizontally placed antenna elements that provide pattern diversity. The proposed antenna has a $-10 \mathrm{~dB}$ bandwidth of $8.9 \mathrm{GHz}(3.1-12 \mathrm{GHz})$ in the UWB and $0.55 \mathrm{GHz}$ $(2.05-2.6 \mathrm{GHz})$ in the ISM band. SAR analysis is investigated to determine the radiation level for on-body applications. The obtained SAR values satisfy the limits recommended by the FCC. The proposed wristband MIMO antenna, due to its low cost, provides user safety on a limited budget.

\section{Data Availability}

The data used to support the findings are available from the corresponding upon request.

\section{Conflicts of Interest}

The authors declare that they have no conflicts of interest.

\section{References}

[1] M. Virili, H. Rogier, F. Alimenti, P. Mezzanotte, and L. Roselli, "Wearable textile antenna Magnetically coupled to flexible active Electronic circuits," IEEE Antennas and Wireless Propagation Letters, vol. 13, pp. 209-212, 2014.
[2] L. Zhang, Z. Wang, and J. L. Volakis, "Textile antennas and Sensors for body-worn applications," IEEE Antennas and Wireless Propagation Letters, vol. 11, pp. 1690-1693, 2012.

[3] P. S. Taylor and J. C. Batchelor, "Finger-worn UHF far-field RFID tag antenna," IEEE Antennas and Wireless Propagation Letters, vol. 18, no. 12, pp. 2513-2517, 2019.

[4] X. Shan and Z. Shen, "Miniaturized UHF/UWB tag antenna for indoor positioning systems," IEEE Antennas and Wireless Propagation Letters, vol. 18, no. 12, pp. 2453-2457, 2019.

[5] Z. Hamouda, J.-L. Wojkiewicz, A. A. Pud et al., "Dual-band elliptical planar conductive polymer antenna printed on a flexible substrate," IEEE Transactions on Antennas and Propagation, vol. 63, no. 12, pp. 5864-5867, 2015.

[6] H. Xiaomu, S. Yan, and G. A. E. Vandenbosch, "Wearable button antenna for dual-band WLAN applications with combined on and off-body radiation patterns," IEEE Transactions on Antennas and Propagation, vol. 65, no. 3, pp. 1384-1387, 2017.

[7] E. F. Sundarsingh, M. Kanagasabai, and V. S. Ramalingam, "Completely integrated multilayered weave electro-textile antenna for wearable applications," International Journal of Microwave and Wireless Technologies, vol. 9, no. 10, pp. 2029-2036, 2017.

[8] H. R. Khaleel, A. Issac, H. Al-Rizzo, and A. Bihnam, "Wearable printed monopole antenna for uwb and ism applications," in Proceedings of the USNC-URSI Radio Science Meeting (Joint with AP-S Symposium), p. 5, Memphis, TN, USA, July 2014.

[9] R. Narayan, S. Ataman, and M. Mathian, "A dual-band planar monopole antenna for $2.4 \mathrm{GHz}$ ISM and UWB Applications," in Proceedings of the IEEE 27th Convention of Electrical and 
Electronics Engineers in Israel, pp. 1-4, Eilat, Israel, November 2012.

[10] X.-L. Li, G.-M. Yang, and Y.-Q. Jin, "Isolation enhancement of wideband vehicular antenna array using fractal decoupling structure," IEEE Antennas and Wireless Propagation Letters, vol. 18, no. 9, pp. 1799-1803, 2019.

[11] A. Alemaryeen and S. Noghanian, "On-body low-profile textile antenna with artificial magnetic conductor," IEEE Transactions on Antennas and Propagation, vol. 67, no. 6, pp. 3649-3656, 2019.

[12] "Properties of silicone rubber," https://www.azom.com/ properties.aspx?ArticleID=920.

[13] R. Singh and G. Kumar, Broadband Planar Monopole Antennas, IIT, Bombay, India, 2004.

[14] K. P. Ray, "Design aspects of printed monopole antennas for ultra-wide band Applications," International Journal of Antennas and Propagation, vol. 2008, Article ID 713858, 8 pages, 2008.

[15] R. Sanyal, P. P. Sarkar, and S. Sarkar, "Octagonal nut shaped monopole UWB antenna with sextuple band notched characteristics," AEU-International Journal of Electronics and Communications, vol. 110, pp. 1434-8411, 2019.

[16] M. S. Sharawi, "Current Misuses and future Prospects for printed multiple-input, multiple-output antenna systems [wireless Corner]," IEEE Antennas and Propagation Magazine, vol. 59, no. 2, pp. 162-170, 2017.

[17] A. Hoque, M. T. Islam, and A. F. Almutairi, "Low-profile slotted metamaterial antenna based on bi slot microstrip patch for 5g application," Sensors, vol. 20, pp. 1-20, 2020.

[18] M. Alibakhshikenari, B. S. Virdee, A. A. Althuwayb et al., "Study on on-Chip antenna design based on metamaterialInspired and substrate-integrated Waveguide properties for Millimetre-wave and $\mathrm{THz}$ integrated-circuit applications," Journal of Infrared, Millimeter and Terahertz Waves, vol. 42, no. 1, pp. 17-28, 2021.

[19] C. Yu, S. Yang, Y. Chen et al., "A super-wideband and high isolation MIMO antenna system using a windmill-shaped decoupling structure," IEEE Access, vol. 8, pp. 115767-115777, 2020.

[20] P. Kumar, S. Urooj, and A. Malibari, "Design and implementation of quad-element super-wideband MIMO antenna for IoT applications," IEEE Access, vol. 8, pp. 226697-226704, 2020.

[21] A. Desai, C. D. Bui, J. Patel, T. Upadhyaya, G. Byun, and T. K. Nguyen, "Compact wideband four element optically transparent MIMO antenna for mm-wave 5G applications," IEEE Access, vol. 8, pp. 194206-194217, 2020.

[22] U. Ullah, I. B. Mabrouk, and S. Koziel, "Enhanced-performance circularly polarized MIMO antenna with polarization/ pattern diversity,” IEEE Access, vol. 8, pp. 11887-11895, 2020.

[23] C.-Y.-D. Sim, H.-Y. Liu, and C.-J. Huang, "Wideband MIMO antenna array design for future mobile devices operating in the 5G NR frequency bands n77/n78/n79 and LTE band 46," IEEE Antennas and Wireless Propagation Letters, vol. 19, no. 1, pp. 74-78, 2020.

[24] Z. Xu and C. Deng, "High-isolated MIMO antenna design based on pattern diversity for $5 \mathrm{G}$ mobile terminals," IEEE Antennas and Wireless Propagation Letters, vol. 19, no. 3, pp. 467-471, 2020.

[25] R. Hussain, M. U. Khan, and M. S. Sharawi, "Design and analysis of a miniaturized meandered slot-line-based quadband frequency agile MIMO antenna," IEEE Transactions on Antennas and Propagation, vol. 68, no. 3, pp. 2410-2415, 2020.
[26] K. Zhang, Z. H. Jiang, W. Hong, and D. H. Werner, "A lowprofile and wideband triple-mode antenna for wireless body area network concurrent on-/off-body communications," IEEE Transactions on Antennas and Propagation, vol. 68, no. 3, pp. 1982-1994, 2020.

[27] A. K. Biswas, S. S. Pattanayak, and U. Chakraborty, "Evaluation of dielectric properties of colored resin plastic button to design a small MIMO antenna," IEEE Transactions on Instrumentation and Measurement, vol. 69, no. 11, pp. 91709177, 2020.

[28] B. Wang and S. Yan, "Design of smartwatch integrated antenna with polarization diversity," IEEE Access, vol. 8, pp. 123440-123448, 2020.

[29] A. Iqbal, A. Smida, A. J. Alazemi, M. I. Waly, N. Khaddaj Mallat, and S. Kim, "Wideband circularly polarized MIMO antenna for high data wearable biotelemetric devices," IEEE Access, vol. 8, pp. 17935-17944, 2020.

[30] A. K. Biswas and U. Chakraborty, “"Compact wearable MIMO antenna with improved port isolation for ultrawideband applications," IET Microwaves, Antennas \& Propagation, vol. 13, no. 4, pp. 344-354, 2019. 